\section{Práticas integrativas e complementares e medicalização social: indefinições, riscos e potências na atenção primária à saúde}

\author{
Complementary and alternative medicine and \\ social medicalization: lack of definitions, risks, \\ and potentials in primary healthcare
}

Medicina complementaria y alternativa y
medicalización social: indefiniciones, riesgos y
potencialidades en la atención primaria en salud
Charles Dalcanale Tesser 1

Daniela Dallegrave 2 doi: 10.1590/0102-311X00231519

\section{Resumo}

As Práticas Integrativas e Complementares em Saúde (PICS) deveriam estar cada vez mais compreendidas no ambiente acadêmico e de pesquisa, dada sua crescente inserção nas instituições de saúde e em pesquisas científicas. Entretanto, comumente há conceituações ou generalizações temerárias na literatura científica brasileira, sendo exemplo a relação das PICS com a medicalização social. O objetivo deste trabalho é discutir o potencial medicalizante e desmedicalizante do uso de PICS, especialmente na atenção primária à saúde (APS). Trata-se de ensaio que sintetiza a indefinição referente ao potencial simultaneamente medicalizante e desmedicalizante de várias PICS, baseado em literatura selecionada, que registra convergências teóricas e empíricas. $O$ exercício de PICS em contexto clínico tem potencial medicalizante, devido ao seu conceito positivo, ampliado e holístico de saúde e sua multidimensionalidade etiológica, podendo gerar o chamado "adoecimento holístico", observado teórica e empiricamente. Tal exercício apresenta também potencial desmedicalizante, dependente do praticante, devido a maior flexibilidade interpretativa, contextualização, singularização e participação do usuário no cuidado, relação clínica mais próxima, valores e tradições de algumas PICS, diversidade de intervenções e seu potencial de enriquecimento do autocuidado. O potencial medicalizante ou desmedicalizante de várias PICS é ativado por seus praticantes, e contexto da APS é favorável ao segundo.

Terapias Complementares; Medicalização; Atenção Primária à Saúde; Saúde Pública

\author{
Correspondência \\ C. D. Tesser \\ Departamento de Saúde Pública, Centro de Ciências da Saúde, \\ Universidade Federal de Santa Catarina. \\ Campus Universitário, Trindade, Florianópolis, SC \\ 88040-900, Brasil. \\ charles.tesser@ufsc.br \\ ${ }_{1}$ Departamento de Saúde Pública, Universidade Federal de \\ Santa Catarina, Florianópolis, Brasil. \\ 2 Universidade Federal do Rio Grande do Sul, Porto Alegre, \\ Brasil.
}




\section{Introdução}

As medicinas tradicionais, complementares e integrativas são discutidas há décadas no campo da pesquisa científica, e o assunto é cada vez mais presente e relevante. Seu uso é grande nos países de alta renda ${ }^{1}$, há crescimento exponencial do assunto em pesquisas científicas ${ }^{2} \mathrm{e}$ há sua progressiva institucionalização nos serviços públicos e privados de saúde. Por isso, seria justificada a expectativa de que sua abordagem acadêmica estivesse se consolidando, aumentando a compreensão e a construção de consensos sobre características relevantes desse universo heterogêneo etiquetado por características ausentes: saberes, cuidados e terapias externas à mainstream medicine 3,4. No Brasil, cunhou-se a designação Práticas Integrativas e Complementares em Saúde (PICS), termo que se generalizou no ambiente do Sistema Único de Saúde (SUS) e que usaremos doravante.

Nas pesquisas na Saúde Coletiva sobre o tema, seriam esperadas uma incorporação e uma sedimentação de discussões e acúmulos conceituais e empíricos sobre PICS, esclarecendo esse fenômeno social que aglutina elementos de revalorização coletiva e institucionalização e que envolve sua oferta progressiva no SUS, especialmente na atenção primária à saúde (APS). Entretanto, artigos e trabalhos acadêmicos brasileiros com afirmativas pouco sustentáveis e excessiva generalização de características virtuosas atribuídas a várias PICS não têm sido raros. Essas afirmativas são radicalmente opostas a outras excessivamente negativas, sobretudo na mídia (que as resumem a efeito placebo, por exemplo). Um artigo de 2016 sobre PICS, por exemplo, afirma: "as práticas integrativas se caracterizam pela interdisciplinaridade e por linguagens singulares, próprias, que em geral se contrapõem à visão altamente tecnológica de saúde que impera na sociedade de mercado" 5 (p. 99); "o repertório de práticas integrativas (...) descende de uma tradição milenar de uso continuado e praticamente inalterado dos mesmos recursos tecnológicos, pautados por natureza interdisciplinar" (p. 100). Em uma busca simples realizada às $17 \mathrm{~h}$ de 13 de Novembro de 2019, ao digitar o título desse artigo no buscador Google Scholar (https://scholar.google.com/ - sem limite de tempo), constatamos que esse trabalho foi citado por 49 publicações, das quais 30 eram artigos científicos: 11 periódicos da Saúde Coletiva (área com mais publicações) e 19 de outros periódicos, a maioria da saúde. Todos se ancoram no artigo citado, sem ressalvas ou críticas.

Uma aproximação mais crítica dessas afirmações acima mencionadas questionaria algumas de suas generalizações: interdisciplinaridade, tradição milenar e contraposição à visão que impera nas sociedades de mercado são atribuídas genericamente às PICS. Porém, nem todas as PICS são de tradição milenar. As milenares não são propriamente interdisciplinares, a não ser talvez pela inexistência de disciplinas (como as concebemos hoje) em sociedades várias de séculos atrás. É difícil sustentar que "as" PICS ou suas linguagens se contrapõem à tecnologia moderna ou ao mercado. Várias PICS, mais antigas, vitalistas e inseridas em racionalidades médicas, na acepção de Luz \& Barros ${ }^{6}$, parecem ser simplesmente indiferentes: desenvolveram suas próprias técnicas, seus saberes e seus insumos para o cuidado. O fato de várias delas serem antigas e vitalistas e de seus insumos serem outros em relação aos produtos industriais contemporâneos não parece lhes tornar "contrapostas" à visão moderna, embora tenham sido assinaladas diferenças profundas e significativas entre vários aspectos das racionalidades médicas vitalistas em relação à racionalidades biomédica 6 . Mesmo que haja uma contraposição em alguns aspectos, isso serve para algumas PICS, não para todas.

Várias PICS mais modernas parecem envolver inovações tecnológicas, ainda que nem tão novas (veja-se a ozonioterapia, por exemplo, incluída recentemente no rol das PICS pelo Ministério da Saúde). Em relação ao mercado, as PICS incluem produtos amplamente comercializados, disponibilizados ao público, comprados e vendidos abertamente. Um exemplo são os suplementos dietéticos não vitamínicos e não minerais, os quais constituem as PICS mais prevalentes em três inquéritos nacionais norte-americanos (com a ressalva de que as vitaminas e as orações ou a espiritualidade não foram investigadas) 7 .

No Brasil, o texto da Política Nacional de Práticas Integrativas e Complementares (PNPIC) 8 facilitou generalizações insustentáveis. No primeiro parágrafo do capítulo 2 da PNPIC, há identificação das PICS com o que a Organização Mundial da Saúde (OMS) e o saber acadêmico chamam de "medicina tradicional, complementar e integrativa" ou "medicina alternativa e complementar". Na segunda e terceira frases desse parágrafo, aparecem enunciados muito citados em artigos científicos brasileiros:

“Tais sistemas e recursos envolvem abordagens que buscam estimular os mecanismos naturais de prevenção de agravos e recuperação da saúde por meio de tecnologias eficazes e seguras, com ênfase na escuta acolhedora, 
no desenvolvimento do vínculo terapêutico e na integração do ser humano com o meio ambiente e a sociedade. Outros pontos compartilhados pelas diversas abordagens abrangidas nesse campo são a visão ampliada do processo saúde-doença e a promoção global do cuidado humano, especialmente do autocuidado" 8 (p. 10).

Características positivas são atribuídas generalizadamente às PICS na segunda frase: estímulo à autocura, tecnologias eficazes/seguras, escuta acolhedora, vínculo terapêutico, integração com o meio ambiente/sociedade. Contudo, o verbo "envolver" deixa a frase ainda defensável, pois é um tanto indeterminado. Já a terceira frase supõe atributos positivos (visão ampliada e promoção do autocuidado) para todas as PICS, o que não procede. Trata-se de documento institucional governamental, e não trabalho científico. Portanto, é compreensível a presença de recursos retóricos, direcionamentos, imprecisões etc. Ocorre que, como é uma política pública, a PNPIC tem efeitos diversos, servindo comumente de referência para trabalhos científicos. Não é raro se ler em artigos e dissertações afirmativas que "as PICS" são seguidas de predicados que "as" (implicitamente todas) qualificam apenas positivamente com base nesse trecho da PNPIC. Pode haver algumas dessas características em várias delas, mas provavelmente não em todas ou em todas as suas aplicações.

O problema é a generalização acrítica, a qual, ao contrário de destacar e discutir potencialidades e virtudes desejáveis de modo específico, as obscurecem com afirmações que podem se aproximar de manifestações panfletárias, dificultando a sua valorização. Na literatura científica, se espera precisão na linguagem, nos conceitos e nas definições, bem como na sustentabilidade conceitual e empírica das afirmações, além de atitude crítica em relação às publicações governamentais. Parcimônia no trato do tema é desejável, sobretudo devido ao seu crescimento nos serviços de APS, que oferecem quase $80 \%$ das PICS praticadas no SUS 9 .

Um tema pouco investigado no Brasil dentro dessa problemática é o caráter ou a ação das PICS em relação ao processo de medicalização. Há alguma menção na literatura científica sobre as PICS serem recursos ou práticas desmedicalizantes, menos medicalizantes ou "alternativas" à medicalização 10,11. Esse tema tem relevância devido ao intenso processo de medicalização social e suas transformações neste século 12, incluindo cuidado clínico curativo e preventivo. Com o envelhecimento populacional, a maior proeminência de doenças crônicas e o apelo à prevenção e promoção, a medicalização da prevenção é um processo avançado que gera demanda adicional aos serviços de APS, já que prevenir doenças é uma das suas tarefas. Embora a prevenção seja genericamente desejável, seu excesso e sua medicalização podem transformar grande número de pessoas saudáveis em doentes, aumentar a iniquidade na distribuição dos recursos (com a priorização de jovens, ricos e saudáveis nos serviços de saúde, em detrimento de velhos, pobres e doentes) 13,14,15 e gerar danos iatrogênicos. Isso tem suscitado propostas de redução da medicalização no cuidado clínico 16 e na prevenção 17 , tornando importante e necessária a discussão sobre que papel as PICS podem ter nesse processo.

Este artigo objetiva discutir o potencial medicalizante e/ou desmedicalizante da prática clínica de várias PICS, contextualizada no cuidado profissional na APS. Isso envolve analisar a interface do conjunto genérico das PICS com o processo de medicalização social, situada no contexto clínico da APS. Do ponto de vista metodológico, trata-se de um ensaio que parte de literatura científica sobre pesquisas empíricas e discussões conceituais sobre esse tema em específico. Não houve pesquisa sistemática de literatura, mas busca artesanal a partir de artigos conhecidos, cujas referências levaram a outros artigos e assim por diante. Também foi usado assistematicamente o recurso da busca de trabalhos recentes que citaram artigos considerados focados centralmente na temática (via Google Scholar - https://scholar.google.com/). A leitura e análise dos artigos visou primeiramente a permitir uma visão e compreensão de conjunto da interface em foco. A suficiência da literatura acessada foi considerada atingida quando um quadro suficientemente claro e convergente se formou, registrando convergências teóricas e empíricas de modo a viabilizar uma matriz conceitual de referência e uma argumentação para discussão do tema, cuja organização segue abaixo.

No próximo tópico, estabelecemos um referencial conceitual sobre os significados da "medicalização social" ou "medicalização", adaptados para o nosso objetivo e coerentes com recentes discussões sobre valorização, reforma e ampliação do conceito 18,19. Em seguida, ensaiamos uma discussão dos potenciais medicalizantes e desmedicalizantes das PICS, com base em argumentos teóricos e estudos empíricos, nacionais e internacionais. Embora a discussão proposta não seja de todo original, estando dispersa, sobretudo, fora do Brasil, ela tem sido relativamente ignorada ou pouco sistematizada na 
Saúde Coletiva, o que empobrece o avanço das pesquisas e análises sobre as PICS no SUS. Este trabatho pretende contribuir para suprir essa lacuna.

\section{Medicalização social e PICS: adaptações conceituais}

Michel Foucault tratou da medicalização social em uma perspectiva ampla, investigando práticas e costumes relacionados a alguns séculos de história na Europa. O filósofo referiu-se à "medicalização indefinida", que significa a ampliação mais recente do escopo da biomedicina para "todo e qualquer aspecto da vida humana” 20 (p. 724). Esse sentido é coerente com o proposto por outros autores, dentre os quais Conrad 21, que definiu medicalização social como a aplicação de saberes, técnicas e tecnologias médicas de cuidado a um determinado problema ou situação, quando isso não era feito anteriormente. Geralmente envolve interpretar problemas, aspectos ou experiências das pessoas como doenças ou transtornos, conforme abordados pela biomedicina, e manejá-los com farmacoterapia e/ou cirurgia. A medicalização é um processo social complexo, em franco progresso, intrínseco à cultura ocidental e que permeia nossa subjetividade 22, intensificado no século XXI 12, com múltiplos agentes envolvidos 23 .

Conrad 21 reconhece que o processo é progressivo e tende a gerar um ocultamento de aspectos conflitivos das relações sociais, por sua transformação em "problemas de saúde" ou "doenças". Destacou três dimensões da medicalização: conceitual (uso do modelo ou abordagem médica na interpelação de um problema ou situação), institucional (organizações adotam aproximações terapêuticas para tratar problemas) e interacional (profissionais definem um problema como clínico ou "de saúde" ou tratam um problema "social" como se fosse uma "doença", na sua interação com os usuários) 24. Neste ensaio, abordaremos apenas esta última dimensão.

Nessa conceituação, a medicalização tem como referência a biomedicina, a primeira e mais poderosa profissão do campo da saúde. Com a proliferação de profissões, porém, hoje podemos considerar o mesmo processo ocorrendo em um sentido mais amplo, relacionado à aplicação de abordagens/ saberes das várias profissões da saúde 25. Para evitar neologismos ("psicologização", "nutricionização" etc.), manteremos o termo "medicalização". Essa é uma primeira adaptação para a nossa discussão.

O conceito acima de Conrad é descritivo, e não valorativo. A medicalização pode ser vantajosa ou desvantajosa, pode ser desfeita (despatologização da homossexualidade), pode ser indesejável, como em adoecimentos banais (resfriados) ou mesmo trágica, como o parto/nascimento, no Brasil, convertido em cesárea em mais de $90 \%$ dos casos nos serviços privados e em mais de 50\% no SUS, com índices alarmantes de violência obstétrica 26.

Uma abordagem crítica e pioneira do tema foi a de Illich 27, para quem a medicalização é essencialmente indesejável e deve ser evitada ou desfeita o quanto possível, especialmente pela consequente redução da autonomia (relativa) e competência na gestão autônoma da maior parte das situações de sofrimento, adoecimento, dor e morte. Junto com essa redução, há aumento de dependência para com a ação profissionalizada. Nesse sentido, a medicalização implica algum prejuízo para a saúde, tomada como grau de liberdade vivida, de competência e de autonomia para enfrentar e manejar as oscilações e vicissitudes da vida, uma visão inspirada em Canguilhem 28 . Ou seja, para Illich, a medicalização significa redução da autonomia e do aumento da dependência da ação profissionalizada em saúde 29.

Illich identificou forte tendência medicalizante na ação médica, cujas consequências iatrogênicas (prejuízos derivados dessa ação) englobam danos clínicos no indivíduo sob cuidado, prejuízos sociais (efeitos difusos de disseminação de comportamentos passivos e demandas por cuidado profissional para situações comuns da vida) e prejuízos culturais (redução da capacidade de pessoas e populações para manejo de grande parte de suas experiências envolvendo sofrimento e dor). Por essas razões, é justificada a ideia geral de que a medicalização deve ser evitada e reduzida o quanto possível, sendo exceções tratadas à parte. Neste ensaio, adotamos esse aspecto da visão de Illich, contextualizado especificamente na dimensão interacional da medicalização.

Outra adaptação conceitual vem da consideração de que características e consequências indesejáveis da medicalização - especialmente iatrogenia cultural com redução da autonomia relativa e geração/aumento de dependência para com o cuidado heterônomo (manejado pelo curador ou terapeuta) - podem ocorrer em abordagens clínicas orientadas por um saber suficientemente espe- 
cializado em saúde-doença, independente de ser ou não referenciado na biomedicina (ou em outras profissões da saúde). Isso é compreensível devido ao fato de que a biomedicina não é a única tradição de saber/prática estruturada nas sociedades. Outros saberes/técnicas de cuidado sobreviveram ou foram desenvolvidos, sendo alguns reconhecidos hoje como sistemas médicos complexos ou racionalidades médicas ${ }^{6}$. Outros são menos complexos e estruturados, em parte fora do manejo autônomo do cidadão comum, reconhecidos como PICS no Brasil, oriundos ou não de uma racionalidade médica.

Adotamos, então, uma segunda ampliação do significado da medicalização, englobando processos ocorridos em ações clínicas de terapeutas referenciados em outras racionalidades médicas ou saberes. Exemplificamos: um praticante de homeopatia ou de acupuntura (que usa referencial chinês tradicional) pode atender uma pessoa e tratá-la com um medicamento homeopático ou com sessões de acupuntura, fomentando dependência do tratamento e do terapeuta, deixando a pessoa tratada menos competente para manejar seu problema de saúde e suas dificuldades na vida. Se usarmos a conceituação de Conrad de medicalização, esses tratamentos não poderiam ser caracterizados como medicalizantes, dado não haver uso da biomedicina. Todavia, se similares efeitos prejudiciais podem ser gerados, devido à possibilidade de medicalização sem biomedicina, essa ampliação é necessária.

Illich também "via a medicalização como independente da racionalidade médica" 30 (p. 919), e era cético sobre usar outros saberes como antídotos para a medicalização: "quanto mais existem diferentes teorias com o poder de diagnosticar e definir um tratamento, mais razões existem para renunciar à responsabilidade de transformar o que, no meio ambiente, faz adoecer (...), e mais a doença se despolitiza" 27 (p. 113).

A medicalização assim ampliada pode ocorrer sob qualquer racionalidade médica ou saber/técnica de cuidado em saúde-doença suficientemente elaborado e manejado por um curador socialmente reconhecido, profissionalizado ou não, para interpretação e tratamento de problemas ou situações de pessoas. Nessa lógica, pode-se dizer que, quando a ação clínica de um curador ou de um conjunto deles mantém (ou induz) maior autonomia e empoderamento de pessoas e populações, não há medicalização, restando preservado o equilíbrio dinâmico entre autonomia e heteronomia. Porém, quando ela reduz a autonomia, desempodera e gera dependência relativa, há medicalização, independente do saber de base usado como referência. Esse ponto converge com o de Camargo Jr. ${ }^{31}$, quando afirma, discutindo o conceito de medicalização, que o uso de PICS "não é sinônimo de desmedicalização" (p. 209).

Também Correia 32 defende o que chama de uma abordagem baseada no conhecimento. Afirma que o conceito de medicalização deve ser amplo o suficiente para incluir os diferentes ramos do conhecimento médico (diferentes racionalidades médicas ou PICS não diretamente relacionadas a uma RM), independentemente do seu status político ou científico na sociedade. Para o autor, "aceitar uma definição inclusiva de medicalização é um passo fundamental. E também reconhecer o fato de que, quando um ramo do conhecimento exerce controle social sobre toda a sociedade, como é o caso da biomedicina no Ocidente, isso não impede que outros ramos também medicalizem comportamentos e condições, mesmo que o façam parcialmente..." 32 (p. 6). Embora Correia não discuta especificamente os aspectos da medicalização acima destacados, sua proposta é convergente e coerente com as adaptações aqui realizadas.

Isso não significa que todos os saberes especializados e técnicas de cuidado praticados por curadores são semelhantes quanto à medicalização e bastaria mudar a direção da sua prática rumo ao estímulo para maior autonomia. Os saberes e técnicas em saúde-doença não são apenas "ferramentas" que se pode usar livremente, de forma medicalizante ou desmedicalizante, mas também não são rígidos a ponto de não permitirem reconstruções, inovações, "deformações" e reorientações nenhumas por seus agentes sociais. No dizer de Merhy 33, envolvendo tecnologias leve-duras e leves, vários desses saberes/técnicas têm alguma maleabilidade e possibilidade de reconstrução e inovação no seu ensino e uso, ainda que limitadas. A limitação vem de valores, cosmovisões, usos preconcebidos e finalidades específicas embutidas na sua estrutura, aprendizado e exercício. Sua prática está mais ou menos atrelada a essas finalidades e valores, viabilizando certas abordagens e efeitos e dificultando ou afastando outros. Como isso pode ocorrer em relação ao potencial de medicalização ou desmedicalização das ações clínicas, quaisquer saberes e técnicas usados no cuidado clínico devem ser examinados quanto ao seu efeito medicalizante ou desmedicalizante, em teoria e nas práticas.

Essa maleabilidade relativa implica outro aspecto conceitual importante para nossa discussão: nem a biomedicina nem as várias PICS têm uma essência fundamental que garanta seu efeito quanto à medicalização ou desmedicalização. Não há um cerne que transcenda a construção, o ensino e a prática social de um saber/técnica,com os sentidos, significados e valores associados. A biomedicina 
e muitas PICS têm potências e limites, características próprias e lógicas de ação, que produzem tendências, facilidades e dificuldades específicas, as quais devem ser avaliadas quanto à medicalização. Por exemplo, é sabido que a biomedicina tem características na sua estrutura de saberes, na sua lógica de operação, nos valores incorporados nas suas técnicas e na tradição de seu ensino e prática social (relativamente homogênea em relação à heterogeneidade das PICS) que a tornam tendencialmente medicalizante. Logo, ela não é uma potente "ferramenta" para desmedicalizar 34,35,36,37, e suas transformações recentes apontam para um acirramento dessa tendência 12.

\section{Podem as PICS ser medicalizantes?}

Ao discutir a contribuição das racionalidades médicas vitalistas e outras PICS para a promoção da saúde, Tesser 38 menciona que uma característica comum a várias delas é que carregam uma noção ou conceito positivo de saúde associado, na literatura, a um holismo tido geralmente como uma virtude. Registra, todavia, que seu foco de ação é no indivíduo. Essa característica de foco individual de grande parte das PICS não é um detalhe desprezível e aparece em estudos sociológicos internacionais como importante para o tema da medicalização.

Ning 39, em recente revisão de literatura, assinala que desde décadas atrás há na sociologia da saúde debate sobre aspectos contraditórios e paradoxais das PICS quanto ao tema do holismo e da medicalização e desmedicalização. Um desses aspectos é o seu foco eminentemente individualista, amplamente convergente com o clima neoliberal atual que enfatiza a responsabilidade individual pelos cuidados à saúde. As PICS tendem a se concentrar na pessoa como responsável ou até culpada por seus comportamentos de saúde, ao passo que determinantes sociais mais amplos da saúde podem ser ignorados 40,41 .

Lowenberg \& Davis 42, em pesquisa na Califórnia (Estados Unidos) com praticantes, pacientes e líderes de algumas PICS, também afirmam a ênfase de as pessoas assumirem responsabilidades por sua própria saúde e bem-estar, na chamada "saúde holística", e acrescentam que a busca de informações, melhorias dietéticas, modificação de comportamento, redução do estresse, exploração espiritual etc. são inseparáveis da própria condição de saúde à qual se aspira.

Procedimentos de desculpabilização dos doentes foram considerados característicos do processo histórico de medicalização e profissionalização do cuidado à saúde, envolvendo a biomedicina. Segundo Parsons 43, importante sociólogo norte-americano, pioneiro em teorizar sobre a função da medicina na sociedade em uma perspectiva funcionalista, ao assumir o papel de doente e aceitar cumpri-lo, submetendo-se às prescrições médicas, a pessoa adoecida é absolvida de sua "culpa". Reintegrase ao sistema social e busca manter sua harmonia rompida pelo adoecimento e suas consequências sobre o comportamento dos indivíduos. Nesse sentido específico, a realocação da responsabilidade na pessoa, atribuída genericamente ao conjunto das PICS, é coerente com a desmedicalização. Porém, Lowenberg \& Davis 42 apontam que esse processo é cheio de ambiguidades: a 'nova' responsabilização dos indivíduos pode ser usada como justificativa para reduzir os serviços públicos de saúde, retirar recursos dos doentes e deficientes e estigmatizá-los. Outra contradição é que os autores observaram que, embora os discursos sejam de responsabilização individual, no campo empírico, a maioria dos pacientes chegava aos terapeutas de PICS sentindo-se tão culpados (culpa desenvolvida na sua prévia interação com profissionais convencionais) que, na prática, a tendência predominante dos terapeutas de PICS era de atenuá-la. Embora os autores reconheçam que, ao reduzir a distância entre curadores e pacientes e estimular a participação destes últimos, deslocando a decisão para eles, várias PICS atuam potencialmente em direção desmedicalizante, seu caráter individualista e sua abordagem etiológica ampliada podem reforçar a medicalização: "o paradoxo da saúde holística em relação à tese da medicalização da sociedade é, portanto, que enquanto uma de suas principais injunções contraria a medicalização, a outra mais do que a apoia" 42 (p. 584).

Esse também é o centro do argumento de Scott 44: por holisticamente ampliar a noção de boa saúde para abranger fatores espirituais, relacionais e emocionais, além dos físicos, os praticantes de PICS podem ser vistos, paradoxalmente, também como uma extensão ou intensificação da medicalização.

Retornando ao Brasil e considerando o contexto de prática das PICS situado na APS no SUS, a APS certamente atenua o clima neoliberal nas relações dos profissionais com os seus usuários vinculados, 
devido ao caráter de serviço público de inserção comunitária. Entretanto, parece inegável que esse clima permeia a sociedade brasileira e, inclusive, não raro, porções da gestão do SUS envolvidas em crescentes experiências de terceirização de seus serviços de saúde.

Camargo Jr. 29 discutiu criticamente a chamada conceituação positiva e ampliada de saúde: a sua generalidade é uma armadilha, pois pode tornar a vida medicalizável indefinidamente, já que se a saúde é quase tudo ou quase tudo tem a ver com ela, então praticamente tudo pode se tornar um problema a ser abordado como de saúde, de modo quase infinitamente medicalizante. Essa não é uma possibilidade ou especulação apenas teórica. Não conhecemos estudos nacionais com esse foco, mas pesquisadores reconheceram fenômenos que concretizam essa possibilidade em outros países.

Investigando terapeutas de PICS atuantes em Boston, que tratavam de mulheres com câncer de mama, Sered \& Agigian 45 identificaram um discurso detalhado e holístico nesses terapeutas sobre causas e fatores causais para esse tipo de câncer, que envolviam potencialmente todas as áreas da vida de uma mulher (e possivelmente suas vidas passadas). Esse reenquadramento etiológico foi chamado pelos autores de "adoecimento holístico": "um processo discursivo através do qual um diagnóstico corporal (câncer de mama) é amplificado para trauma, infortúnio, defeitos de caráter, espiritualidade atrofiada, más escolhas alimentares, problemas de gênero e um ambiente degradado" 45 (p. 627). Os autores observaram em campo empírico que tanto PICS quanto a medicina convencional colocam enorme ênfase na responsabilidade do indivíduo pela doença e há pouca ênfase nos aspectos socioestruturais e ambientais. Tal crítica deve ser relativizada em muitas situações graves ou de grande sofrimento que demandam interação clínica e ação terapêutica dirigidas a cuidar, curar ou aliviar, desviando-se da abordagem de determinantes sociais e ambientais (pelo menos temporariamente), o que vale tanto para a biomedicina quanto para as PICS. Porém, nos discursos da maioria dos praticantes de PICS investigados, os critérios de melhora eram muito vagos, o que pode ser considerado um paradoxo: o próprio holismo das narrativas etiológicas significa que as narrativas de eficácia correspondentes tendem a ser vagas e abertas, deixando os pacientes (talvez) em um estado de adoecimento holístico crônico, para além de suas doenças diagnosticadas biomedicamente. Tais pacientes dificilmente eram curados ou equilibrados o suficiente em todas as suas dimensões energéticas, emocionais, espirituais, alimentares, ambientais etc., afastando a perspectiva de finalização do tratamento heterônomo.

A junção de individualismo da abordagem com a cronicidade decorrente das múltiplas dimensões do adoecimento holístico foi observada e reconhecida como tendo um caráter medicalizante, associado à visão também presente em várias PICS de que a doença pode ser "uma oportunidade para aprender, crescer e curar em vários níveis em que o paciente pode não saber que precisava de cura" 45 (p. 627).

No Brasil, alguns estudos de ofertas de PICS no SUS se aproximam indiretamente dessa discussão. Lima et al. 46, ao estudarem um serviço municipal especializado em PICS, observaram o fenômeno de quase não haver 'altas' no serviço: os usuários ficavam ativamente revezando pelas terapias, com alta aderência, independentemente dos motivos iniciais de chegada ao serviço. Isso poderia ser explicado, ainda que parcialmente, pela conjunção do "adoecimento holístico" e da busca e do aprendizado intermináveis pelo equilíbrio/harmonia, inerente a várias PICS, com a boa relação e fortes vínculos entre profissionais de PICS e usuários, o que pode gerar resultados em parte medicalizantes.

Em outro estudo 47 sobre a experiência de usuários de acupuntura no SUS, na APS e em serviços especializados, observou-se que os aspectos educativos das experiências dos usuários com a acupuntura nos ambulatórios especializados eram similares às com os demais serviços convencionais. Havia uma maior exploração de aspectos pedagógicos de saberes e outras técnicas da medicina chinesa potencialmente empoderadores e talvez menos medicalizantes na APS, com encontros coletivos dedicados a esses aspectos (automassagens, exercícios respiratórios etc.).

Podemos responder agora à questão do subtítulo deste tópico: sim, a prática de várias PICS pode ser medicalizante. Devido ao seu holismo diagnóstico, curativo e etiológico, ao potencial de produzir "adoecimento holístico", à abordagem individualista, à melhor relação terapeuta-paciente (que implica maior confiança e por vezes maior liberdade de interpretação para o terapeuta), ao contexto contemporâneo neoliberal, aos interesses de mercado e à cultura consumista, várias PICS podem ser praticadas em direção medicalizante e algumas pesquisas já detectaram isso.

O contexto da APS atenua alguns desses fatores, mas por si só não parece suficiente para eliminar essa possibilidade, mesmo porque a biomedicina (e sua tendência pró-medicalização ${ }^{34}$ ) geralmente domina o imaginário profissional nesses serviços de saúde, influenciando também os usuários. Além 
disso, outro fator frequentemente importante pró-medicalização é a já antiga e crescente medicalização da cultura e da sociedade 22 . Tal cultura medicalizada mantém um tônus, uma insegurança e uma angústia crescentes agindo como uma força ou pressão medicalizante, mais ou menos presente nos grupos sociais e pessoas, induzindo usuários e profissionais à medicalização como uma via rápida, supostamente desejável, quase natural e de "menor esforço" 48.

Reconhecer o potencial medicalizante das PICS (e da biomedicina) pode auxiliar os terapeutas, sobretudo os da APS, na reflexão sobre a produção de modos de cuidado em direção a maior liberdade e autonomia. Dessa forma, profissionais e serviços de saúde podem funcionar como refúgios ocasionais de cura/cuidado em situações que excedem a competência autônoma, provendo acompanhamento em situações mais graves e/ou crônicas, visando a autonomia progressiva, ou simplesmente atuando como conselheiros que devem ser comprometidos com o aumento da autonomia e da liberdade vivida com responsabilidade dos usuários 49 .

\section{Podem as PICS ser desmedicalizantes?}

O primeiro cuidado na resposta é evitar generalizações indevidas. Como vimos, há indefinições e contradições teóricas e empíricas no exercício de várias PICS, mas também há vários elementos facilitadores da desmedicalização: tendência de maior horizontalização de relações clínicas, maior estímulo à participação dos pacientes, abordagem ampliada e holística dos problemas, abordagem de aspectos espirituais e valorização das narrativas e experiências individuais, e isso indiretamente facilita uma reflexão e compreensão dos contextos de vida e singularização das vivências, de modo potencialmente desmedicalizador. Pesquisas empíricas com várias PICS mostram que o quadro de relações entre terapeutas e pacientes é mais afetivo (diminuição na neutralidade afetiva que contrasta com as práticas convencionais). Os componentes afetivos e expressivos das interações clínicas observadas são descritos com maior compreensão, empatia, carinho e calor 42.

Levando em conta as indefinições mencionadas anteriormente quanto a algumas dessas características potencialmente desmedicalizantes, uma resposta à pergunta do subtítulo deste tópico pode ser: depende de como as PICS são praticadas. Se essa é uma resposta cautelosa, ela é positiva e otimista em comparação com a biomedicina, a qual é altamente limitada e cheia de dificuldades quanto ao seu potencial desmedicalizante 34 .

A condicionalidade mencionada acima provavelmente oscila conforme o contexto, as PICS e os seus praticantes, dependendo variavelmente desses três fatores. Em contextos marcadamente comerciais ou de mercado, as forças contextuais e os aspectos contraditórios das PICS facilitam a direção medicalizante, devido também aos interesses econômicos dos terapeutas. Já nos serviços da APS no SUS, em tese, os valores e o contexto favorecem a direção desmedicalizante, caso elas sejam direcionadas para esse lado. A recente ampliação de cinco modalidades de PICS, incluídas na PNPIC em 2006, para 29, nos últimos anos 50,51, reforça a possibilidade da exploração da direção desmedicalizante nesse contexto, dada a diversidade de abordagens. Entretanto, é importante observar compromissos e interesses privados que, não raro, se fazem presentes na gestão do SUS, direcionando decisões, políticas e ações em vários níveis, incluindo as práticas profissionais (por exemplo, quando há a chamada dupla militância, em que profissionais atuam simultaneamente no SUS e fora dele).

As modalidades de PICS influenciam seu potencial desmedicalizante, sendo ele provavelmente maior nas que podem ser experimentadas, aprendidas e praticadas pelos usuários sobre si mesmos e/ ou seus pares, em sua rede de relações sociais. Assim, a acupuntura, uma técnica eminentemente heterônoma, será menos facilmente desmedicalizante do que um grupo de Liang Gong (uma sequência de movimentos de relativamente fácil aprendizado e de prática individual ou grupal).

Certamente, também o terapeuta tem um grande papel no potencial desmedicalizante, devido ao maior espaço de protagonismo para ele em várias PICS e ao caráter mais artesanal do cuidado ali presente. Sua maior responsabilidade interpretativa e a singularização permitidas por algumas PICS e racionalidades médicas vitalistas sugerem que a ação do terapeuta deve ser destacada, sobretudo nas PICS praticadas em atendimentos clínicos individuais. Se várias PICS permitem um maior protagonismo dos seus terapeutas na intepretação e singularização do cuidado, a concretização da direção desmedicalizante depende ainda mais desse protagonismo: ela não é automática nem garantida. Logo, 
qualquer apologia generalizadora das virtudes de várias PICS como desmedicalizantes deve ser evitada. Por isso, o uso de PICS no cuidado clínico individual e coletivo em sentido desmedicalizante, sobretudo na APS, demanda clareza mínima sobre a medicalização e maior protagonismo desmedicalizante dos profissionais, que prepara o terreno de sua atuação no sentido de ele usar e explorar PICS em sentido empoderador e desmedicalizante, apoiando os usuários nesse sentido.

A resposta positiva é relativamente cética e condicionada ao protagonismo do terapeuta, ou à sua capacidade de compreender a medicalização e minimizá-la ou evitá-la, ou ainda, talvez, à presença de uma intuição ou valor ético de cuidado emancipatório no terapeuta e/ou na sua prática. Todavia, tal resposta é promissora porque permite prever efeitos positivos de iniciativas educacionais que se dediquem a melhorar as práticas na APS e ensinar algumas PICS selecionadas a esses profissionais de modo associado com a discussão e prática de evitar a medicalização e os danos iatrogênicos, isto é, a prevenção quaternária 52 . O menor potencial de dano iatrogênico atribuído genericamente às PICS em relação à biomedicina apoia essa previsão.

Tesser \& Barros 30 (p. 918), discutindo as PICS como recurso de manejo da medicalização, também apontam que "parece menos iatrogênico e mais enriquecedor para a cultura de saúde-doença dos usuários do SUS contingentes de pessoas 'homeopatizadas', 'acupunturadas', 'yoguizadas', 'meditantes' ou 'fitoterapeutizadas', dentre outras, do que uma população continental medicalizada a exigir do SUS intervenções químico-cirúrgicas para qualquer incômodo". Para os autores, a pluralização terapêutica do SUS e da APS via oferta de PICS tem um positivo, embora limitado, potencial desmedicalizante, podendo pelo menos consistir em algo como uma estratégia de redução de danos.

A maior horizontalidade nas relações entre vários praticantes de PICS e usuários, com mais participação dos últimos nas decisões e nos cuidados, facilita a exploração de uma outra força potencialmente sinérgica com a direção desmedicalizante: o protagonismo dos usuários, em uma parceria solidária que é reconhecida como necessária e urgente, de forma unânime por clínicos e pela saúde pública. Isso ficou realçado com as discussões sobre promoção da saúde em torno da categoria empowerment ou empoderamento. Mais genericamente, a relação da promoção da saúde com várias PICS foi discutida por Tesser 38 , que viu em várias PICS contribuições férteis e pouco exploradas para a promoção à saúde. Sá et al. ${ }^{53}$, em revisão recente da literatura, concluíram positivamente na mesma direção.

A ativação e o fomento dessa força - o protagonismo e a agência dos usuários - é importante, complexa e merece atenção para além do escopo deste artigo, mas tecemos alguns comentários a respeito. Uma característica relevante de várias PICS relacionada ao protagonismo dos usuários e com íntima interface com a questão da medicalização é sua maior riqueza de significação, de comunicação, de estímulo e de variedade de práticas para o autocuidado. Isso é substancialmente desejável em problemas crônicos e também nas miríades de problemas cotidianos de saúde e sofrimentos existenciais muito prevalentes na APS e de boa evolução, chamados por vezes de inespecíficos, frequentemente sobremedicalizados. Isso também é relevante para pessoas saudáveis de qualquer idade, como enriquecimento cultural em cuidado e saúde.

O autocuidado, embora possa ser considerado promotor de autonomia, no geral, e, de certa forma, redutor da medicalização, também não é isento de indefinição quanto a esse tema. Em um extremo de uma polaridade, o autocuidado pode ser considerado autorreferido, quando é decidido e praticado a partir da matriz de saberes, hábitos de vida, aprendizados pessoais e práticas autóctones da cultura e/ ou da experiência de vida da pessoa (e de seus familiares ou próximos). Também pode ser incorporado a esse universo de modo fundamentado, experimentado ou validado autonomamente pela própria pessoa. Nesse caso ele pode ser identificado com a parte cultural e cognitivamente autóctone do que Menéndez ${ }^{54}$ chamou de autoatenção.

No outro extremo dessa polaridade, o autocuidado pode ser heterorreferido, quando orientado por um saber especializado dominado por especialistas, terapeutas ou profissionais de saúde, mesmo que esse saber/técnica se dissemine capilarmente na sociedade e nos comportamentos individuais. Um exemplo é a realização de rastreamentos (ou exames de check up), cuja fundamentação é impermeável à validação empírica pelas pessoas e radica-se geralmente alhures, na ciência ou no saber profissional e especializado.

Entre esses extremos, pode haver um processamento e incorporação pelas pessoas, culturas e sociedades de práticas de autocuidado originalmente heterorreferidas que migram para uma zona 
cinzenta ou mesmo talvez para mais perto do outro polo, tornando-se relativamente autorreferidas, como talvez seja o caso da higiene bucal (escovar os dentes) por exemplo, parcialmente. Há casos em que há certo paralelismo, com convergência relativa entre o autocuidado autorreferido e o heterorreferido, embora eles permaneçam distintos e com suas próprias lógicas, como a orientação quanto à necessidade de movimento corporal para manutenção da saúde e prevenção (comum a várias tradições culturais), cuja versão científica heterorreferida é a orientação e por vezes prescrição de atividade física regular.

Com efeito, o projeto ou ambição (sob uma perspectiva política, ainda que micropolítica) das orientações biomédicas para autocuidado heterorreferido é que ele entre para a zona cinzenta e seja até mesmo incorporado pela parte autorreferida do autocuidado. Essa incorporação pode ser considerada uma descrição simplificada do mecanismo de poder disciplinar capilarizado, socialmente exercido pela relação biopolítica de que fala Foucault 55 , que funciona via socialização primária e secundária das pessoas, auto e heterovigilância e redes sociais capilarizadas de micropoderes, que reproduzem práticas (inclusive de autocuidado) e relações sociais que constituem a própria cultura. Isso é um dos pilares mais gerais do processo de medicalização social inicial de que falou Foucault, do qual somos constituídos e que está sedimentado em sociedades e populações ocidentais urbanizadas e industrializadas 20,22 .

Ocorre que o apelo à prevenção e à promoção da saúde, inclusive o circulante em parte dos profissionais da APS, geralmente recorre aos saberes biomédicos que, no seu cerne, informam práticas de autocuidado heterorreferidas, cujo potencial de promoção de autonomia e desmedicalização é limitado, já que são dependentes do saber alheio e remetidas à adesão ao que é cientificamente recomendado. A oferta de várias PICS porta a indefinição de poder significar estímulo ao autocuidado heterorreferido mas também ao autorreferido. Nesse último caso, isso se dá via enriquecimento da cultura das pessoas e comunidades por meio de envolvimento pessoal com práticas de autocuidado com PICS, sua experimentação e validação por conta própria (diferentemente do autocuidado orientado por saberes biomédicos, que são relativamente pobres no estímulo à construção do autocuidado autorreferido ${ }^{34)}$.

Assim, há uma vantagem de várias PICS em relação à biomedicina quanto ao potencial de estímulo ao autocuidado, mas essa vantagem só concretiza a plenitude de seu potencial desmedicalizante, empoderador e emancipador se promover e estimular o autocuidado autorreferido. Para isso, o tipo de abordagem, de significação, de experimentação proposta e o relacionamento com os usuários na APS é fundamental, no sentido de direcionar as práticas de autocuidado com PICS para um autorreferenciamento, um aprendizado existencial empoderador, um alargamento do espaço de liberdade para experimentar, sentir, refletir, se conhecer, poder fazer, pensar, aprender etc. Assim, a competência e os saberes autóctones devem ser apoiados e enriquecidos sem pressão, sem exercício unidirecional de autoridade, sem chantagem emocional ou atemorização - comuns nos casos de doença crônica (se não acontecer, pode desencadear derrame, infarto, pé diabético etc.).

Há estudos fundamentando empiricamente que essa possibilidade se concretiza na APS brasileira em alguns locais. As observações e os achados de Antunes 56, em pesquisa sobre o que conceitualizou como práticas corporais integrativas, indicaram que PICS que envolvem de forma intensificada e peculiar a atenção e o corpo, em que há experimentação pessoal e corporal ativa e em coletivos (grupos na APS de yoga, danças circulares, Lian Gong etc.), parecem mobilizar potenciais de autonomia, socialização e ressubjetivação nos participantes, para além de seus resultados sobre sintomas e doenças, de modo provavelmente não medicalizante e promotor de autocuidado. Também Galvanese 57 relatou que práticas corporais e meditativas ofertadas na APS são relacionadas ao favorecimento da autonomia (pela construção de referências de saúde via autoconhecimento), à união entre promoção e cuidado terapêutico e ao apoio ao acesso a bens culturais e espaços de cidadania.

Por outro lado, o autocuidado promovido via PICS pode deslizar para práticas heterorreferidas (maquiadas por saberes mais holísticos), ao modo de a pessoa aderir ao que é prescrito ou recomendado, independentemente de qual saber, técnica ou terapeuta é a fonte da orientação. Isso se complica ainda mais ao notarmos que hoje há certa convergência relativamente frequente entre orientações biomédicas e por parte de praticantes ou de técnicas de PICS para o autocuidado. Sendo inviável maior desenvolvimento desse tema neste momento, assinalamos a potência de várias PICS para o incremento do autocuidado autorreferido, se assim dirigidas. Também destacamos sua indefinição e 
possibilidade de estimularem autocuidado heterorreferido, autovigilante e, de certa forma, potencialmente medicalizante.

Outras características de várias PICS facilitadoras do protagonismo desmedicalizador são a sua flexibilidade e diversidade epistemológica e técnica: várias delas, sobretudo as racionalidades médicas vitalistas, têm formas e versões diversas de cuidado e autocuidado, desde altamente sofisticadas e especializadas para uso clínico heterônomo até formas simplificadas e populares de cuidado autônomo, passando por estágios intermediários. Isso significa que é possível conectar interpretações especializadas com noções menos especializadas e populares, ações especializadas com práticas caseiras de simples realização e aprendizado, ou já presentes na cultura popular, de forma mais acessível e passível de fomento à autonomia do que na biomedicina ${ }^{38}$. Embora isso não seja garantido, é uma possibilidade a ser ativa e intencionalmente explorada pelos profissionais do SUS e especialmente da APS.

\section{Considerações finais}

Várias PICS podem ser usadas para "combater a opressão social, mas também podem ser usadas para evitar abordá-la" 44 (p. 143). "Embora o [seu] 'holismo' desempenhe um papel necessário na criação de uma forma socialmente progressista de cuidado clínico, parece claro que ele não é suficiente" 44 (p. 142). O mesmo pode ser dito em relação ao uso de PICS para a desmedicalização. As virtudes de várias PICS podem e devem ser exploradas para minimizar a medicalização e quiçá desmedicalizar, mas isso depende dos terapeutas e do uso que fazem delas. Elas podem mais facilmente (relativamente à biomedicina) ser usadas nessa direção, mas podem ser usadas em direção oposta.

Já passou a hora de melhor qualificarmos e especificarmos o uso de PICS que vem crescendo lentamente no cuidado institucional no SUS e na APS. Se elas parecem ter eficácias e efetividades antes não suspeitadas, merecem também cuidadosa análise e discussão sobre seu potencial medicalizante e desmedicalizante. Este último não se concretiza pela simples oferta de quaisquer PICS na APS ou no SUS, mas provavelmente depende do tipo de prática e do modo como é desenvolvida pelos profissionais em suas interações com os usuários. A maioria das PICS no SUS está dispersa na APS e foi pouco investigada. Pesquisas empíricas com foco na relação entre (des)medicalização e PICS merecem ser realizadas no SUS.

\section{Colaboradores}

C. D. Tesser contribuiu na concepção e projeto, análise e interpretação dos dados, na redação e revisão crítica relevante do conteúdo intelectual, na aprovação final da versão a ser publicada e é responsável por todos os aspectos do trabalho na garantia da exatidão e integridade de qualquer parte da obra. D. Dallegrave contribuiu na análise e interpretação dos dados, na revisão crítica relevante do conteúdo intelectual, na aprovação final da versão a ser publicada, e é responsável por todos os aspectos do trabalho na garantia da exatidão e integridade de qualquer parte da obra.

\section{Informações adicionais}

ORCID: Charles Dalcanale Tesser (0000-00030650-8289); Daniela Dallegrave (0000-0002-21511497).

\section{Referências}

1. Kemppainen LM, Kemppainen TT, Reippainen JA, Salmenniemi ST, Vuolanto PH. Use of complementary and alternative medicine in Europe: health-related and sociodemographic determinants. Scand J Public Health 2018; 46:448-55.

2. Treister-Goltzman Y, Peleg R. Trends in publications on complementary and alternative medicine in the medical literature. J Altern Complement Med 2015; 12:111-5.

3. Gray RE. Four perspectives on unconventional therapies. Health: An Interdisciplinary Journal for the Social Study of Health, Illness and Medicine 1998; 2:55-74.

4. World Health Organization. WHO traditional medicine strategy: 2014-2023. Geneva: World Health Organization; 2013.

5. Telesi-Jr E. Práticas integrativas e complementares em saúde, uma nova eficácia para o SUS. Estud Av 2016; 30:99-112. 
6. Luz MT, Barros NF, organizadores. Racionalidades médicas e práticas integrativas em saúde: estudos teóricos e empíricos. Rio de Janeiro: Instituto de Medicina Social, Universidade do Estado do Rio de Janeiro; 2012.

7. Clarke TC, Black LI, Stussman BJ, Barnes PM, Nahin RL. Trends in the use of complementary health approaches among adults: United States, 2002-2012. Natl Health Stat Report 2015; 79:1-16.

8. Departamento de Atenção Básica, Secretaria de Atenção à Saúde, Ministério da Saúde. Política Nacional de Práticas Integrativas e Complementares no SUS - PNPIC-SUS. Brasília: Ministério da Saúde; 2006.

9. Tesser CD, Sousa IMC, Nascimento MC. Práticas Integrativas e Complementares na atenção primária à saúde brasileira. Saúde Debate 2018; 42 Suppl 1:174-88.

10. Aguiar J, Kanan L, Masiero A. Práticas Integrativas e Complementares na atenção básica em saúde: um estudo bibliométrico da produção brasileira. Saúde Debate 2019; 43:1205-18.

11. Guimarães M, Nunes J, Velloso M, Bezerra A, Sousa I. As práticas integrativas e complementares no campo da saúde: para uma descolonização dos saberes e práticas. Saúde Soc 2020; 29:e190297.

12. Clarke AE, Mamo L, Fosket JR, Fishman JR, Shim JK. Biomedicalization: technoscience, health, and illness in the U.S. Durham: Duke University Press; 2010.

13. Gérvas J, Starfield B, Heath I. Is clinical prevention better than cure? Lancet 2008; 372:1997-9.

14. Heath I. Who needs health care-the well or the sick? BMJ 2005; 330:954-6.

15. Heath I. In defence of a national sickness service. BMJ 2007; 334:19.

16. Tesser CD. Cuidado clínico e sobremedicalização na atenção primária à saúde. Trab Educ Saúde 2019; 17:e0020537.

17. Tesser CD. Por que é importante a prevenção quaternária na prevenção? Rev Saúde Pública 2017; 51:116.

18. Busfield J. The concept of medicalization reassessed. Sociol Health Illn 2017; 39:759-74.

19. Williams S, Coveney C, Gabe J. The concept of medicalisation reassessed: a response to Joan Busfield. Sociol Health Illn 2017; 39:775-80.

20. Zorzanelli RT, Cruz MGA. O conceito de medicalização em Michel Foucault na década de 1970. Interface (Botucatu) 2018; 22:721-31.

21. Conrad P. The medicalization of society. Baltimore: Johns Hopkins University Press; 2007.

22. Rose N. Beyond medicalisation. Lancet 2007; 369:700-1.

23. van Dijk W, Faber MJ, Tanke MAC, Jeurissen PPT, Westert GP. Medicalisation and overdiagnosis: what society does to medicine. Int J Health Policy Manag 2016; 5:619-22.

24. Conrad P. Medicalization and social control. Annu Rev Sociol 1992; 18:209-32.

25. Tesser CD, Pezzato LM, Silva EN. Medicalização social e odontologia: possíveis aproximações. Saúde Soc 2015; 24:1349-61.
26. Sens MM, Stamm AMNF. A percepção dos médicos sobre as dimensões da violência obstétrica e/ou institucional. Interface (Botucatu) 2019; 23:e170915.

27. Illich I. A expropriação da saúde: nêmesis da medicina. 4a Ed. São Paulo: Nova Fronteira; 1981.

28. Canguilhem G. O normal e o patológico. Rio de Janeiro: Forense-Universitária; 1978.

29. Camargo Jr. KR. As armadilhas da "concepção positiva de saúde”. Physis (Rio J.) 2007; 17:6376.

30. Tesser CD, Barros NF. Medicalização social e medicina alternativa e complementar: pluralização terapêutica do Sistema Único de Saúde. Rev Saúde Pública 2008; 42:914-20.

31. Camargo Jr. KR. Medicalização: um quadro de referência. In: Pinheiro R, Silva Jr. AG, organizadores. Por uma sociedade cuidadora. Rio de Janeiro: Instituto de Medicina Social, Universidade do Estado do Rio de Janeiro/Abrasco; 2010. p. 209-16. (Série Cidadania do Cuidado).

32. Correia T. Revisiting medicalization: a critique of the assumptions of what counts as medical knowledge. Frontiers in Sociology 2017; 2:14.

33. Merhy EE. Um ensaio sobre o médico e suas valises tecnológicas: contribuições para compreender as reestruturações produtivas do setor Saúde. Interface (Botucatu) 2000; 4:109-16.

34. Tesser CD. Medicalização social (II): limites biomédicos e propostas para a clínica na atenção básica. Interface (Botucatu) 2006; 10:34762.

35. Tesser CD. Três considerações sobre a "má medicina”. Interface (Botucatu) 2009; 13:27386.

36. Tesser CD. A verdade na biomedicina, reações adversas e efeitos colaterais: uma reflexão introdutória. Physis (Rio J.) 2007; 17:465-84

37. Camargo Jr. KR. Biomedicina, ciência \& saber: uma abordagem crítica. São Paulo: Editora Hucitec; 2003.

38. Tesser CD. Práticas complementares, racionalidades médicas e promoção da saúde: contribuições poucos exploradas. Cad Saúde Pública 2009; 25:1732-42.

39. Ning AM. How holistic is complementary and alternative medicine (CAM)? Examining selfresponsibilization in CAM and biomedicine in a neoliberal age. Med Res Arch 2018; 6:1-11.

40. Givati A. Performing 'Pragmatic Holism': professionalisation and the holistic discourse of non-medically qualified acupuncturists and homeopaths in the United Kingdom. Health (London) 2015; 19:34-50.

41. Ning A. How 'Alternative' is CAM? Rethinking conventional dichotomies between biomedicine and Complementary/Alternative Medicine. Health (London) 2013; 17:135-58.

42. Lowenberg J, Davis F. Beyond medicalisationdemedicalisation: the case of holistic health. Sociol Health Illn 1994; 16:579-99.

43. Parsons T. The social sistem. Londres: Routledge \& Kegan Paul; 1967. 
44. Scott A. Paradoxes of Holism: some problems in developing an anti-oppressive medical practice. Health (London) 1999; 3:131-49.

45. Sered S, Agigian A. Holistic sickening: breast cancer and the discursive worlds of complementary and alternative practitioners. Sociol Health Illn 2008; 30:616-31.

46. Lima KMSV, Silva KL, Tesser CD. Práticas integrativas e complementares e relação com promoção da saúde: experiência de um serviço municipal de saúde. Interface (Botucatu) 2014; 18:261-72

47. Silva ER, Tesser CD. Experiência de pacientes com acupuntura no SUS e (des)medicalização social. Cad Saúde Pública 2013; 29:2186-96.

48. Tesser $\mathrm{CD}$. A atenção à saúde e a construção cotidiana da cultura e da medicalização social. In: Tesser CD, organizador. Medicalização social e atenção à saúde no SUS. São Paulo: Editora Hucitec; 2010. p. 52-73.

49. Nogueira RP. A saúde pelo avesso. Natal: Seminare Editora; 2003.

50. Ministério da Saúde. Portaria no 702, de 21 de março de 2018. Altera a Portaria de Consolidação no 2/GM/MS, de 28 de setembro de 2017, para incluir novas práticas na Política Nacional. Diário Oficial da União 2018; 22 mar.

51. Departamento de Atenção Básica, Secretaria de Atenção Básica, Ministério da Saúde. Ampliação da PNPIC. Informe/Maio de 2017. http://189.28.128.100/dab/docs/portaldab/ documentos/informe_pics_maio2017.pdf (acessado em 14/Abr/2020).
52. Norman AH, Tesser CD. Quaternary prevention: a balanced approach to demedicalisation. Br J Gen Pract 2019; 69:28-9.

53. Sá RF, Nogueira J, Guerra VA. Traditional and complementary medicine as health promotion technology in Brazil. Health Promot Int 2019; 34 Suppl 1:i74-i81.

54. Menendez EL. Modelos de atención de los padecimientos: de exclusiones teóricas y articulaciones prácticas. Ciênc Saúde Colet 2003; 8:185-207.

55. Foucaul M. Microfísica do Poder. 18a Ed. Rio De Janeiro: Graal Editora; 1979.

56. Antunes PC. Práticas corporais integrativas: experiências de contracultura na atenção básica e emergência de um conceito para o campo da saúde [Tese de Doutorado]. Porto Alegre: Universidade Federal do Rio Grande do Sul; 2019.

57. Galvanese ATC, Barros NF, d'Oliveira AFPL. Contribuições e desafios das práticas corporais e meditativas à promoção da saúde na rede pública de atenção primária do Município de São Paulo, Brasil. Cad Saúde Pública 2017; 33:e00122016. 


\begin{abstract}
Complementary and Alternative Medicine (CAM) need to be increasingly understood in the academic and research setting, given their growing inclusion in health institutions and scientific studies. However, vague definitions or broad generalizations are common in the Brazilian scientific literature, an example of which is the relationship between CAM and social medicalization. This study aims to discuss the medicalizing and de-medicalizing potential of the use of CAM, especially in primary healthcare (PHC). This essay summarizes the underlying lack of definition concerning the medicalizing and de-medicalizing potential of various CAM, based on the selected literature, which reports theoretical and empirical convergences. The exercise of CAM in the clinical context has a medicalizing potential, due to its positive, expanded, and holistic conception of health and its etiological multidimensionality, potentially generating so-called "holistic illness", which has been reported theoretically and empirically. CAM also have de-medicalizing potential, depending on the practitioner, due to greater interpretative flexibility, contextualization, singularization, users' participation in the care, closer clinical relationship, the values and traditions of some CAM, diversity of interventions, and the potential for enrichment of self-care. The medicalizing or de-medicalizing potential of various CAM is activated by their practitioners, and the context of PHC tends to favors the de-medicalizing potential.
\end{abstract}

Complementary Therapies; Medicalization; Primary Health Care; Public Health

\section{Resumen}

Las Medicina Complementaria y Alternativa (MCA) deberían estar cada vez más comprendidas en el ambiente académico y de investigación, dada su creciente inserción en las instituciones de salud y en investigaciones científicas. No obstante, comúnmente existen conceptualizaciones o generalizaciones temerarias en la literatura cientifica brasileña, siendo un ejemplo la relación de las MCA con la medicalización social. El objetivo de este trabajo es discutir el potencial medicalizante $y$ desmedicalizante del uso de MCA, especialmente en la atención primaria en salud (APS). Se trata de un ensayo que sintetiza la indefinición referente al potencial simultáneamente medicalizante y desmedicalizante de varias MCA; basado en literatura seleccionada, que registra convergencias teóricas y empíricas. El ejercicio de MCA en un contexto clínico tiene potencial medicalizante, debido a su concepto positivo, ampliado y holístico de salud y su multidimensionalidad etiológica, pudiendo generar el denominado "padecimiento holístico", observado teórica y empíricamente. Tal ejercicio presenta también potencial desmedicalizante, dependiente del practicante, debido a una mayor flexibilidad interpretativa, contextualización, singularización, así como la participación del usuario en el cuidado, una relación clínica más cercana, valores y tradiciones de algunas MCA, diversidad de intervenciones y su potencial de enriquecimiento con el autocuidado. El potencial medicalizante o desmedicalizante de varias MCA se activa mediante sus practicantes y el contexto de la APS es favorable al segundo.

Terapias Complementarias; Medicalización; Atención Primaria de Salud; Salud Pública
Recebido em 02/Dez/2019

Versão final reapresentada em 30/Abr/2019 Aprovado em 29/Jun/2020 